\title{
CORRIGENDUM
}

\section{Routine vaccination practice after adult and paediatric allogeneic haematopoietic stem cell transplant: a survey of UK NHS programmes}

PDE Miller, TI de Silva, R Skinner, M Gilleece, A Peniket, A Hamblin, D Greenfield, C Anthias, K Peggs, A Madrigal and JA Snowden on behalf of the BSBMT Clinical Trials Committee

Bone Marrow Transplantation (2017) 52, 1082; doi:10.1038/bmt.2017.87

Correction to: Bone Marrow Transplantation (2017) 52, 775-777; doi:10.1038/bmt.2016.362; published online 23 January 2017

Since the publication of this article, it has been noted that an acknowledgement was inadvertently not included on the paper.
The acknowledgement is now given here:

AP acknowledges funding from The Haematology and Stem Cell Theme of the Oxford Biomedical Research Centre (BRC).

The authors would like to apologise for this error. 